\title{
EVALUATION OF SHEAR BOND STRENGTH OF NANOPARTICLES GLASS CARBOMER AND HIGH VISCOSITY GLASS IONOMER IN PRIMARY TEETH DENTIN (IN VITRO STUDY)
}

Noha Y Mohammed ${ }^{1} B D S$, Ali A Sharaf ${ }^{2} M S c, P h D$, Dalia M Talaat ${ }^{3} M S c$, PhD, Seham A Hanafi $^{4} M S c, P h D$

\begin{abstract} characteristics in comparison with conventional GICs. viscosity glass ionomer (Fuji IX GP) dentin surface and the bonded material was measured using a universal testing machine. value (2.870). There was a highly significant difference in shear bond strength values between both groups $(\mathrm{p}=0.000)$. may be salutary in GICs selection by dental practitioners.

KEY WORDS: Shear bond strength, Aging, Glass Carbomer, Primary Dentin.

1- Bachelor of Dentistry, Faculty of Dentistry, Alexandria University, Alexandria, Egypt.

2- Professor of Pediatric Dentistry, Faculty of Dentistry, Alexandria University, Alexandria, Egypt.

3- Associate Professor of Pediatric Dentistry, Faculty of Dentistry, Alexandria University, Alexandria, Egypt.

4- Professor of Dental Biomaterials, Faculty of Dentistry, Alexandria University, Alexandria, Egypt.
\end{abstract}

INTRODUCTION: Different techniques can be utilized in vitro to evaluate the durability of the bond strength to tooth structure. Shear bond strength test is one of these methods which have been widely used. Glass carbomer has been introduced with claims of improved physical

OBJECTIVES: The aim of the study was to compare and evaluate the shear bond strength of glass carbomer to primary dentin versus a high

MATERIAL AND METHODS: Twenty primary molar teeth extracted for orthodontic purposes or exfoliated by normal shedding were collected according to specific criteria from public hospitals in Alexandria and outpatient clinic of the Faculty of Dentistry, Alexandria University. Crown surfaces of the included teeth were mounted in acrylic blocks then, ground with water-cooled silicon carbide abrasive papers successively to obtain flat dentin surfaces. The prepared specimens $(n=20)$ were divided into two groups according to the glass ionomer cement (GIC) bonded to the dentin surface (10/ each group): group I (Fuji IX GP) and group II (Glass Carbomer). Shear bond strength (SBS) between

RESULTS: The results revealed that, Fuji IXGP group recorded the highest mean SBS value (6.624) while, Glass Carbomer recorded mean

CONCLUSIONS: The high viscosity glass ionomer was higher in shear bond strength than glass carbomer glass ionomer and this finding

\section{INTRODUCTION}

The use of bonded restorations in children has a significant importance in the present day restorative dentistry. Since they are adhesive to the tooth surface, they greatly reduce the removal of the tooth structure and also reduce micro-leakage thus minimizing discolorations, post-operative sensitivity and the risk of secondary caries formation (1-4).

The use of glass-ionomer cement to restore primary molars provides opportunity to reduce the cavity size by relying on the adhesive properties of these materials. The term glass ionomer cement (GIC) should be applied only to a material that involves a significant acid-base reaction as part of its setting reaction, where the acid is a water soluble polymer and the base is a special glass (5-7).

The original GICs consist of an aqueous solution of poly acrylic acid at a concentration of about $45 \%$ which reacts with a powder consisting of calcium fluoroaluminosilicate glass (8). Since GICs were introduced, these materials have undergone several formula changes in order to make it more suitable for clinical use and to improve its physical and mechanical properties. Therefore, broad categories of GICs are available today such as, conventional, metal-modified and resin-modified GICs. The latter two categories were developed in an attempt to overcome the problems of moisture sensitivity and low mechanical properties associated with the conventional materials but at the same time to retain some of their clinical advantages. On the other hand, improvements within the conventional GICs have produced a subgroup of high viscosity GICs (9).

The development of glass ionomer cements focused on a higher powder-to-liquid ratio, a lower water content, and nano particles leading to the high viscosity glass ionomer cements which could be packable like amalgam and reveal enhanced flexural strength characteristics (10-12).

Saito et al (13) reported that, Fuji IX was introduced in the mid-1990s and known as condensable or high viscous GIC. They have higher strength, greater wear resistance and flexural strength than conventional GIC. In addition, they are less sensitive to moisture contamination and leach more fluorides. Fuji IX was used as reference material as it is the most frequently reported material in the in-vivo and in-vitro studies (14).

One of the most important advances in the dental material field is the application of nanotechnology. Rastelli et al (15) defined nanotechnology as the production and manipulation of materials and structures with particles size in the range of about $0.1-100 \mathrm{~nm}$ by various physical or chemical methods providing a cosmetically acceptable restoration with excellent mechanical properties. These interesting advances led to the development of glass-ionomer based filling material called glass carbomer cement which has been introduced with claims of improved physical characteristics in comparison with conventional GICs (16). It was reported 
that, the addition of hydroxyapatite (HAp) and fluorapatite (FAp) enhance the mechanical properties of the GICs (17, 18). In addition, the nano-sized particles should facilitate the strengthening of the material through an increased particle surface area in contact with the glass-carbomer liquid (19).

Usually, the performance standards for assessing restorative materials usually involve the measurements of compressive strength, diameter tensile strength, flexural strength, flexural modulus, color stability, fluoride release and adhesive bond strength (20).

Knight (21) reported that, adhesiveness of restorative materials to tooth structure is an important factor in current restorative technique. It prevents microleakage, secondary caries, marginal discolorations and pulpal damage. Wilson et al (22) demonstrated that the chemical adhesion of GIC to enamel and dentin is achieved by reaction of phosphate ions in the dental tissue with carboxylate groups from the polyacrylic acid and it has been cited as the most important advantage of the GICs.

Fowler et al (23) illustrated that, adhesions are usually evaluated by the determination of tensile and shear bond strength (SBS) and identified the bond strength as the load required for fracturing the bond interface divided by the cross-sectional area of the bonded area. Many factors affect the bond strength values such as, the dentin substrate, the storage conditions and the test method. Swift et al (24) stated that, bonding to dentin has been less predictable because of the wet tubular ultra-structure and organic composition of the dentin substrate. In addition, Dennison et al (25) pointed out that, there are many reasons which lead to lower bond strength of primary teeth such as, lower concentrations of calcium and phosphorus in the primary teeth than for permanent teeth, the numerical tubule concentration is greater in permanent teeth than primary teeth and the diameter of dentinal tubules is larger close to the pulpal surface $(0.4-0.5 \mathrm{~mm})$ in permanent teeth than in primary teeth, leading to decreased dentinal permeability in primary teeth.

Suresh (26) reported that shear bond strength assumes much importance to restorative materials clinically as the major dislodging forces at the tooth restoration interface have shearing effect. Therefore, high shear bond strength implies better bonding of the material to the tooth.

In the meantime there are limited published data on the clinical performance of glass carbomer thus, in-vitro tests may contribute with valuable insights into the physicalmechanical properties of this material. Therefore, the aim of this study was to evaluate the shear bond strength of a new generation of glass ionomer (Glass Carbomer) to primary dentin versus a high viscosity glass ionomer (Fuji IX) after 24 hours in artificial saliva. The null hypothesis tested was that, there is no difference in the shear bond strength to primary dentin between Glass Carbomer and Fuji IX.

\section{MATERIALS AND METHODS}

Sample size estimation: Using a power of $94 \%$ to detect a significant difference in mean shear bond strength between the two groups of extracted primary teeth dentin bonded with glass carbomer glass ionomer cement and high viscosity glass ionomer cement Fuji IX. A sample size of 10 specimens per group was the minimum required and it was calculated using IBM SPSS sample power program version 3.0.1
Twenty primary molars, extracted for orthodontic reason or exfoliated were collected from public hospitals in Alexandria and outpatient clinic of the Faculty of Dentistry, Alexandria University. Teeth were stored in refrigerated saline solution for maximum 3 months as recommended by the International Standards Organization (ISO) norms until required for use (27).

Teeth were cleaned from tissue remnants and debris using periodontal curettes then polished with slurry of pumice and water then they were carefully examined with a magnifying lens. Teeth with presence of cracks and developmental defects were excluded from the study (28).

Crowns of the collected teeth were separated from the roots at cemento-enamel junction (29). Custom made cylindrical metallic molds of $14 \mathrm{~mm}$ diameter and $20 \mathrm{~mm}$ length were filled with chemically polymerizing acrylic resin. Each crown was embedded horizontally in the acrylic resin making the buccal surface facing upwards. After curing of the acrylic resin, the specimens were removed from the molds and the convex buccal surfaces of the crowns were gently mechanically ground with water cooled silicon carbide abrasive papers or discs to obtain flat dentin surface (29). The prepared specimens were randomly divided into two groups according to the material bonded to the dentin surface. Group I (control group) Fuji IX GP(GC Corporation, Tokyo, Japan), whereas, group II (test group) glass carbomer(Glass Carbomer Products, Leiden, Netherlands) was the material used (Table 1).

For creating a standardized bonding area for both materials, a hole of $3 \mathrm{~mm}$ in diameter, was punched in a double sided adhesive tape which then adhered to the ground dentin surface. A plastic cylindrical shaped mold with internal diameter of $3 \mathrm{~mm}$ and height of $2 \mathrm{~mm}$ was placed coinciding with the central hole, delimiting the area to be bonded (30).

Both materials were activated, mixed and applied according to the manufacturer's instructions which included a pre conditioning step with $10 \%$ poly acrylic acid (GC Dentin conditioner GC Corporation, Tokyo, Japan) to the dentin surfaces of group I (Fuji IX GP group) then, the mixed capsules were placed in the applicator and extruded from the capsules into the plastic mold and were packed until the plastic mold was full. After that application of the specific surface coat of each material was done.

Samples for both groups were stored in artificial saliva (31) 24 hours in an incubator at $37^{\circ} \mathrm{C}$. Finally, all specimens were subjected to shear bond test (SBS) using a universal testing machine (Comten, industries USA.). The specimens were oriented so that the stainless steel knife of the universal testing machine was perpendicular to the interface between the tooth surface and the bonded material. The knife was used to apply load at a crosshead speed of $0.5 \mathrm{~mm} / \mathrm{min}$ until debonding. Then, shear bond strength was calculated in Mega Pascal (MPa) according to the following relation: bond strength $(\mathrm{MPa})=\frac{\mathrm{N} \text { (load) }}{\mathrm{A}\left(\text { surface area in } \mathrm{mm}^{2}\right)}$ The surface area (A) was calculated from the following equation: $\mathrm{A}=$ лr2

\section{Mode of failure assessment}

All the deboned surfaces of the specimens were examined by two examiners under a stereomicroscope (SZ-CTY Olympus, Japan) at magnification $30 \times$ to record the mode of failure. After examination by both examiners the mode of failure was determined after agreement of both examiners, failure mode was identified as (33) (fig.1) 
1. Adhesive failure, if no observable glass ionomer remained on the dentin surface.

2. Cohesive failure, if visible amounts of glass ionomer remained on the dentin surface.

3. Mixed failure, if a mixture of both modes of failure was observed

Table (1): Material Manufacturer and Composition

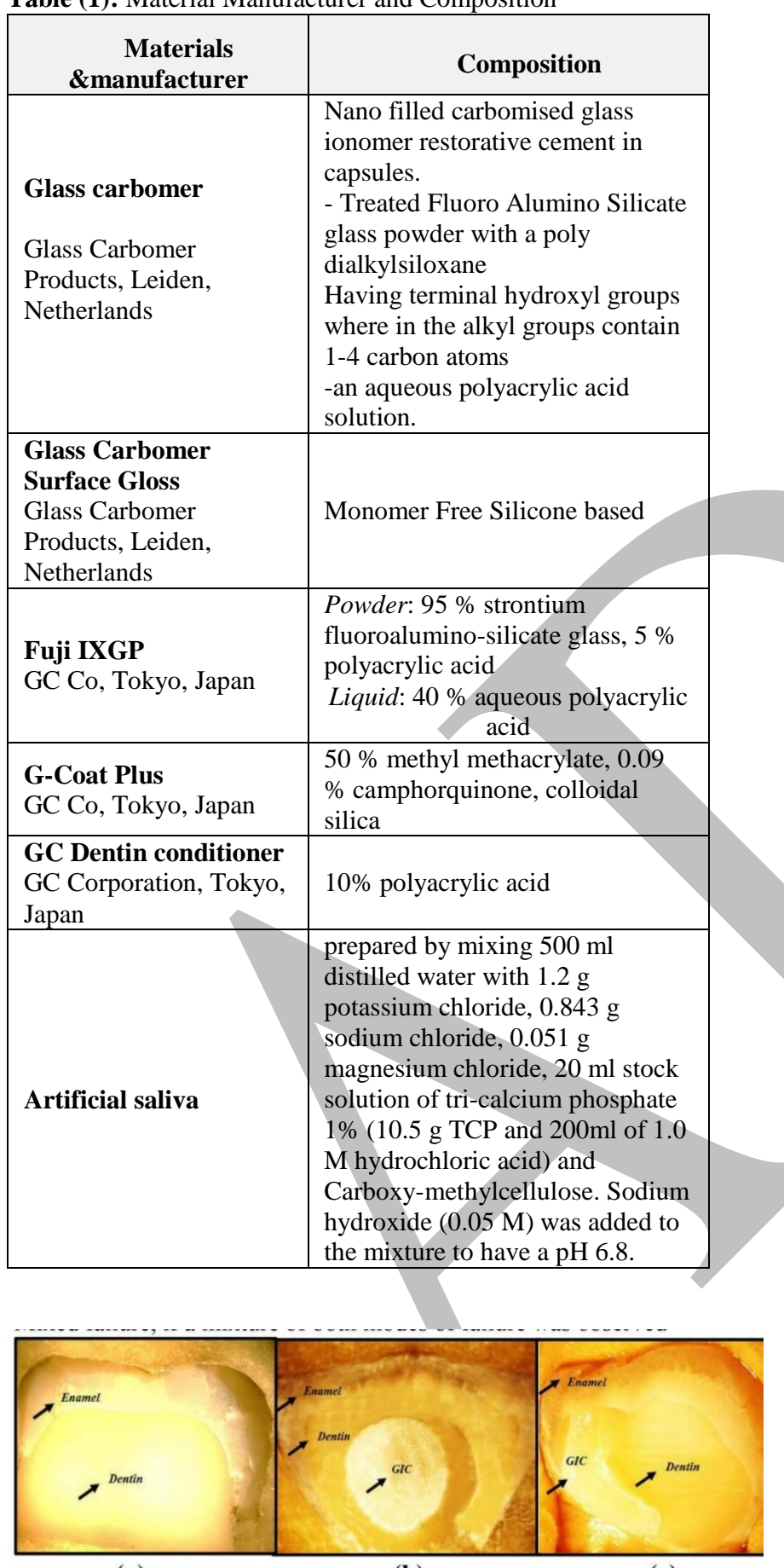

(a)

(b)

(c)

Figure 1: Stereomicroscope of the debonded areas: (a) Adhesive failure, no observable glass ionomer on the dentin surface. (b) Cohesive failure, visible amounts of glass ionomer remained on the dentin surface. (c) Mixed failure, a mixture of both adhesive and cohesive failures.

\section{STATISTICAL ANALYSIS}

Data were collected and entered to the computer using SPSS (Statistical Package for Social Science) program for statistical analysis (ver. 21). Data were entered as numerical or categorical, as appropriate. When Kolmogorov-Smirnov test revealed no significance in the distribution of variables, parametric statistics was carried out (32). Comparisons were carried out between the two studied groups using independent t test. Box and Whiskers was used. Chi-square test was used to measure association between qualitative variables. Monte Carlo correction was carried out when indicated. In the present study an alpha level was set to 5\% with a significance level of $95 \%$.

\section{RESULTS}

Comparing the shear bond strength (MPa) between the two groups the results revealed that Fuji IX GP group (group I) was higher in the mean shear bond strength values (6.624) than glass carbomer group (group II) (2.870) with statistical significance difference $(\mathrm{p}=0.000)$ (table 2 , fig. 2

Comparison between the two groups regarding the 3 mode of failures, revealed no statistically significance difference between them. (Table 3)

Table 2: Comparison of the mean values of the shear bond strength in MPa of Fuji IX GP and Glass Carbomer cements

\begin{tabular}{|c|c|c|}
\hline & Fuji IXGP & $\begin{array}{c}\text { Glass } \\
\text { carbomer }\end{array}$ \\
\hline Minimum & 5.000 & 2.000 \\
\hline Maximum & 7.800 & 3.900 \\
\hline Mean & 6.624 & 2.870 \\
\hline 95\% CI for mean & 5.913-7.334 & $2.345-3.394$ \\
\hline Std. Deviation & 0.9927 & .7331336 \\
\hline Median & 6.630 & 2.560000 \\
\hline KS test & $\begin{array}{c}\mathrm{D}=0.190 \\
\mathrm{p}=0.200 \mathrm{NS}\end{array}$ & $\begin{array}{c}\mathrm{D}=0.234 \\
\mathrm{p}=0.130 \mathrm{NS}\end{array}$ \\
\hline $\begin{array}{l}\text { Levene's test for } \\
\text { equality of variances }\end{array}$ & \multicolumn{2}{|c|}{$\mathrm{F}=0.133, \mathrm{p}=0.719 \mathrm{NS}$} \\
\hline $\begin{array}{l}\text { Independent-samples t } \\
\text { test }\end{array}$ & \multicolumn{2}{|c|}{$\mathrm{t}=9.619, \mathrm{p}=0.000 *$} \\
\hline 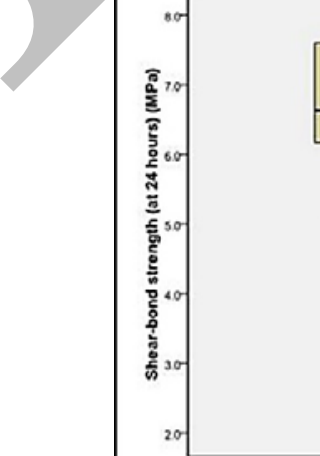 & & $\begin{array}{c}T \\
\perp\end{array}$ \\
\hline & Group & iss cartomer \\
\hline
\end{tabular}

Figure 2: Box and whisker graph for comparison of shear bond strength (Mega Pascal) of Glass Carbomer and Fuji IX GP cements. The thick line in the middle of the box represents the median, the box represents the inter-quartile range (from $25^{\text {th }}$ to $75^{\text {th }}$ percentiles) and the whisker represents the minimum and maximum values.

\section{DISCUSSION}

In the current study the tested materials were, high viscosity Fuji IXGP glass ionomer cement compared with Glass Carbomer which is a new innovation of glass ionomer 
cement. Both cements are encapsulated chemically cured GICs.

Upon comparing the two groups, the null hypothesis was rejected. There was a highly statistical significance difference in the values of shear bond strength of the two used materials in favor of the control group and this result was in accordance with a study by Olegario et al (16). Shebl et al (27) compared the shear bond strength of glass carbomer with one resin modified glass ionomer (Ketac Nano) and one conventional glass ionomer (Ionofil) to enamel surfaces of permanent teeth and the results revealed that, glass carbomer recorded the lowest values of shear bond strength compared with the other two materials tested.

Table (3): Comparison between the two groups regarding the 3 mode of failure

\begin{tabular}{|c|c|c|c|}
\hline & $\begin{array}{l}\text { Fuji IX } \\
\text { (group I) }\end{array}$ & $\begin{array}{l}\text { Glass Carbomer (group } \\
\text { II) }\end{array}$ & $\begin{array}{c}\text { Test of } \\
\text { significance }\end{array}$ \\
\hline \multicolumn{4}{|c|}{\begin{tabular}{|l} 
At 24 hours \\
\end{tabular}} \\
\hline Cohesive & $7(70.0 \%)$ & $4(40.0 \%)$ & \multirow{3}{*}{$\begin{array}{l}X^{2}=3.818 \\
P_{(M C)}=0.240 \mathrm{NS}\end{array}$} \\
\hline \begin{tabular}{|l|} 
Mixed \\
\end{tabular} & $3(30.0 \%)$ & $3(30.0 \%)$ & \\
\hline \begin{tabular}{|l} 
Adhesive \\
\end{tabular} & $0(0.0 \%)$ & $3(30.0 \%)$ & \\
\hline
\end{tabular}

The difference in SBS in the two groups could be due to the application of dentin conditioner which was applied in group I and not in group II according to the manufacturer instructions of both materials. Pre conditioning step may affect the results as the bond strength of the glass-ionomer cement to tooth structure can be enhanced greatly by the use of suitable conditioners for the pre-treatment of enamel and dentin. These substances contain a variety of functional groups capable of hydrogen bonding to tooth material, which ensure effective cleaning and wetting of the substrate surfaces (1).

According to Meerbeek et al, (34) Fuji IX group has two-fold bonding mechanism as, the short polyalkenoic acid pre-treatment cleans the tooth surface; it removes the smear layer and exposes collagen fibrils up to about 0.5-1 m depth then, glass-ionomer components inter-diffuse and establish a micro-mechanical bond. This is in addition to the chemical bonding which is obtained by ionic interaction of the carboxyl groups of the polyalkenoic acid with calcium ions of hydroxyapatite that remains attached to the collagen fibrils which in turn increase the resistance to hydrolytic degradation (35).

On the other hand, a study by Carvalho et al (36) showed that, the shear bond strength of Fuji IX GP was lower than Ketac Molar with statistical significance difference. This difference in the results could be due to using Ketac Molar while in our study we used Glass Carbomer cement.

Considering the association between the different modes of failure found in the result of the current study it was noticed that, the 3 mode of failures were detected by mean of stereomicroscope and there was no statistically significance difference between the two groups regarding the 3 modes of failure detected in both group.

No conclusive results can be found in the literature due to variations on the specimens' dimensions, storage medium time and cross-head speeds of tests. From the previously cited studies, one can find out that, Fuji IX GP can resist the dislodging forces in the oral cavity especially in the atraumatic restorative treatment cases due to its high shear bond strength values recorded. Also, regarding Glass Carbomer a preconditioning step may be needed to improve its adhesion to dentin.

\section{CONCLUSIONS}

From the present in vitro study it was concluded that the mean shear bond strength of Glass Carbomer cement is lower than Fuji IX GP. This information may help the dental practitioner in appropriate material selection.

\section{ACKNOWLEDGEMENT}

The authors would like to thank Dr. Elsayed Amr Basma for helping in accomplishment of the statistical analysis.

\section{CONFLICT OF INTEREST}

The authors declare that they have no conflict of interest.

\section{REFERENCES}

1. Powis D, Follerås T, Merson S, Wilson A. Materials Science Improved Adhesion of a Glass Ionomer Cement to Dentin and Enamel. J Dent Res. 1982; 61: 1416-22.

2. Yap A, Tan A, Goh A, Goh D, Chin K. Effect of surface treatment and cement maturation on the bond strength of resin-modified glass ionomers to dentin. Oper Dent. 2002; 28: 728-33.

3. Triana R, Prado C, Garro J, Garcia-Godoy F. Dentin bond strength of fluoride-releasing materials. Am J Dent. 1994; 7: 252-4.4.Safar J, Davis R, Overton J. Effect of saliva contamination on the bond of dentin to resin-modified glass-ionomer cement. Oper Dent. 1998; 24: 351-7.

5. Davidson CL, Mjör IA. Advances in glass-ionomer cements, Chicago: Quintessence Publishing Co, Inc; 1999.

6. Albers H. Tooth-colored Restoratives. Santa Rosa. CA: Alto books; 1996.

7. Mount GJ, Hume WR. Preservation and restoration of tooth structure, London: Mosby Limited; 1998.

8. Nicholson JW. Chemistry of glass-ionomer cements: a review. Biomaterials. 1998; 19: 485-94.

9. Sidhu S. Glass-ionomer cement restorative materials: a sticky subject? Aust Dent J. 2011; 56: 23-30.

10. Williams J, Billington R, Pearson G. The comparative strengths of commercial glass-ionomer cements with and without metal additions. Br Dent J. 1992; 172: 279-82.

11. Holst A. A 3-year clinical evaluation of Ketac-Silver restorations in primary molars. Swed Dent J. 1995; 20: 209-14.

12. Guggenberger R, May R, Stefan K. New trends in glassionomer chemistry. Biomaterials. 1998; 19: 479-83.

13. Saito S, Tosaki S, Hirota K. Characteristics of glassionomer cements. Advances in glassionomer cements, Chicago: Quintessence; 1999. pp 15-50.

14. Bonifácio C, Kleverlaan C, Raggio D, Werner A, De Carvalho R, Van Amerongen W. Physical-mechanical properties of glass ionomer cements indicated for atraumatic restorative treatment. Aust Dent J. 2009; 54: 233-7.

15. Rastelli AN, Jacomassi DP, Faloni APS, Queiroz TP, Rojas SS, Bernardi MIB, et al. The filler content of the dental composite resins and their influence on different properties. Microsc Res Tech. 2012; 75: 758-65.

16. Olegário IC, Malagrana APVFP, Kim SSH, Hesse D, 
Tedesco TK, Calvo AFB, et al. Mechanical properties of high-viscosity glass ionomer cement and nanoparticle glass carbomer. J Nanomater. 2015; 2015: 37.

17. Lucas ME, Arita K, Nishino M. Toughness, bonding and fluoride-release properties of hydroxyapatite-added glass ionomer cement. Biomaterials. 2003; 24: 3787-94.

18. Moshaverinia A, Ansari S, Moshaverinia M, Roohpour N, Darr JA, Rehman I. Effects of incorporation of hydroxyapatite and fluoroapatite nanobioceramics into conventional glass ionomer cements (GIC). Acta Biomater. 2008; 4: 432-40.

19. Koenraads H, Van der Kroon G, Frencken J. Compressive strength of two newly developed glass-ionomer materials for use with the Atraumatic Restorative Treatment (ART) approach in class II cavities. Dent Mater. 2009; 25: 5516.

20. Braem MJ, Lambrechts P, Gladys S, Vanherle G. In vitro fatigue behavior of restorative composites and glass ionomers. Dent Mater. 1995; 11: 137-41.

21. Knight G, McIntyre J. The effect of silver fluoride and potassium iodide on the bond strength of auto cure glass ionomer cement to dentine. Aust Dent J. 2006; 51: 42-5.

22. Wilson A, Prosser H, Powis D. Mechanism of adhesion of polyelectrolyte cements to hydroxyapatite. J Dent Res. 1983; 62: 590-2.

23. Fowler C, Swartz M, Moore B, Rhodes B. Influence of selected variables on adhesion testing. Dent Mater. 1992; 8: 265-9.

24. Swift Jr EJ, Perdigao J, Heymann HO. Bonding to enamel and dentin: A brief history and state of the art, 1995 . Quintessence Int. 1995; 26: 95-110.

25. Dennison JB. Dentin bonding: SEM comparison of the dentin surface in primary and permanent teeth. Pediatr Dent. 1997; 19: 246-52.26. Suresh K, Nagarathna J. Evaluation of shear bond strengths of fuji II and fuji IX with and without salivary contamination on deciduous molars-an In vitro study. AOSR. 2011; 1: 139-45.

27. Shebl E, Etman W, Genaid TM, Shalaby M. Durability of bond strength of glass-ionomers to enamel. Tanta Dental Journal. 2015;12(1):16-27.

28. Murthy SS, Murthy GS. Comparative Evaluation of Shear Bond Strength of Three Commercially Available Glass Ionomer Cements in Primary Teeth. J Int Oral Health. 2015;7:103.

29. Konno ANK, Sinhoreti MAC, Consani S, Sobrinho LC, Consani RLX. Storage effect on the shear bond strength of adhesive systems. Braz Dent J. 2003;14:42-7.

30. Hashimoto M, Ito S, Tay F, Svizero N, Sano H, Kaga M, et al. Fluid movement across the resin-dentin interface during and after bonding. J Dent Res. 2004;83:843-8.

31. Konno ANK, Sinhoreti MAC, Consani S, Sobrinho LC, Consani RLX. Storage effect on the shear bond strength of adhesive systems. Braz Dent J. 2003;14:42-7.

30. Hashimoto M, Ito S, Tay F, Svizero N, Sano H, Kaga M, et al. Fluid movement across the resin-dentin interface during and after bonding. J Dent Res. 2004;83:843-8.

31. Crisp S, Ferner A, Lewis B, Wilson A. Properties of improved glass-ionomer cement formulations. J Dent. 1975; 3: 125-30.

32. Field A. Discovering Statistics Using SPSS. ed n, editor. London, California, New Delhi: SAGE Publications Ltd; 2006.
33. De Munck J, Van Landuyt K, Peumans M, et al. A critical review of the durability of adhesion to tooth tissue: methods and results. J Dent Res 2005;84: 118-32.

34. Van Meerbeek B, Vargas M, Inoue S, Yoshida Y, Peumans M, Lambrechts P, et al. Adhesives and cements to promote preservation dentistry. Oper Dent. 2001; 26: 119-44.

35. Yoshida Y, Van Meerbeek B, Nakayama Y, Snauwaert J, Hellemans L, Lambrechts P, et al. Evidence of chemical bonding at biomaterial-hard tissue interfaces. J Dent Res. 2000;79:709-14.

36. Carvalho T-S, van Amerongen W-E, de Gee A, Bönecker M, Sampaio F-C. Shear bond strengths of three glass ionomer cements to enamel and dentine. Med Oral Patol Oral Cir Bucal. 2011;16:e406-10. 